\title{
Kaposiform Hemangioendothelioma in the Thoracic Spine: A Case Report and Review of the Literature
}

\author{
KELECHI ESEONU, FRCS, MSC (Oxon), HANNY ANWAR, FRCS \\ Royal National Orthopaedic Hospital, Stanmore, London, United Kingdom
}

\begin{abstract}
Background: Kaposiform hemangioendothelioma (KHE) is a rare, locally aggressive vascular tumor of childhood. It has been most commonly reported in the trunk, retroperitoneum, and extremities, but cases involving the head and neck have been described. While thought to have limited metastatic potential, it is associated with Kasabach-Merritt syndrome (KMS), a consumptive coagulopathy and profound thrombocytopenia that is associated with significant mortality. Twelve cases of KHE with bony involvement have previously been reported. Of these, only 2 involved the spine, and both were managed with medical therapy alone.

Case Presentation: We report the first case of spinal KHE causing spinal cord compression managed with surgical excision presented in the literature to date.

Conclusions: There are a number of treatment modalities outlined in the literature. The lack of a consensus is due to the varying methods of presentation, difficulty in diagnosis, and disease rarity. Our case highlights the potential speed of local growth of this tumor, meaning that excision may be a technical challenge, especially when there is epidural extension. Treating clinicians should be aware of the risk of progression beyond the initial tumor boundaries to involve new vertebrae.
\end{abstract}

Tumor

Keywords: kaposiform hemangioendothelioma (KHE), Kasabach-Merritt syndrome (KMS), vascular tumor, malignant cord compression

\section{BACKGROUND}

Kaposiform hemangioendothelioma (KHE) is a rare, locally aggressive vascular tumor of childhood and adolescence with equal gender ratio. ${ }^{1}$ It was first described by Zuckerberg et $\mathrm{al}^{2}$ in 1992 . It has been most commonly reported in the trunk, retroperitoneum and extremities, but cases involving the head and neck have been described. ${ }^{3-5}$ It classically originates on the skin with a solitary red to purple plaque with poorly defined margins. ${ }^{6,7}$

It has limited metastatic potential and is associated with Kasabach-Merritt syndrome (KMS), a consumptive coagulopathy associated with the risk of catastrophic hemorrhage from invasion into local structures. ${ }^{8,9}$

Twelve cases of KHE with bony involvement have been reported. Of these, only 2 involved the spine, and both were managed with medical therapy alone (Table). We report a case of KHE presenting with back and leg pain without cutaneous changes or coagulopathy (KMS). This is the first case of spinal KHE causing neurological compromise managed with surgical excision presented in the literature to date. ${ }^{10}$

\section{CASE PRESENTATION}

A 5-year-old previously well girl complained of sudden onset of bilateral lower limb weakness and back pain following a fall. Observations and blood results were unremarkable.

Imaging showed an L1 compression fracture and a left-sided lobular soft tissue mass with extradural spinal cord compression. The mass maximally measured $5 \mathrm{~cm}$ cranio-caudally and extended into the posterior elements (Figure 1). Magnetic resonance imaging (MRI) revealed isointense signal abnormality on T1-weighted images and hyperintense signal abnormality on T2-weighted images (Figures 2 and 3). The tumor circumferentially encased the theca.

She was given a 3-month course of high-dose oral corticosteroids at the admitting hospital in the Middle East, which led to the development of severe Cushingoid types of features and seizures. The 
Table. Existing reports of Paediatric kaposiform hemangioendothelioma with bony involvement in the medical literature to date.

\begin{tabular}{|c|c|c|c|c|c|c|c|}
\hline Study & Age & Sex & Location & $\begin{array}{l}\text { Cutaneous } \\
\text { Lesions? }\end{array}$ & $\begin{array}{c}\text { Kasabach- } \\
\text { Merritt } \\
\text { Phenomenon? }\end{array}$ & Treatment & Outcome \\
\hline Lyons et al ${ }^{1}$ & $2 y$ & Male & Temporal bone, neck & Yes & No & Excision & ANED \\
\hline Lisle et $\mathrm{al}^{10}$ & $6 \mathrm{y}$ & Female & T11-L2 vertebrae & No & No & Thalidomide, celecoxib & AWD \\
\hline \multirow[t]{2}{*}{ Ma et $\mathrm{al}^{11}$} & $9 \mathrm{y}$ & Female & Femur & No & No & Excision & ANED \\
\hline & 5 yrs & Male & Humerus & No & No & Excision & ANED \\
\hline Lalaji et $\mathrm{al}^{12}$ & $1 \mathrm{y}$ & Female & $\begin{array}{l}\text { Temporal bone, lateral mass, } \\
\text { C1 vertebra, } \\
\text { occipital bone, ear }\end{array}$ & Yes & Yes & Oral prednisolone & Unknown \\
\hline Gruman et al ${ }^{13}$ & $2 \mathrm{y}$ & Female & Mandible, maxilla, cheek & Yes & No & Interferon- $\alpha 2 b$, prednisolone & AWD \\
\hline \multirow[t]{2}{*}{$\begin{array}{l}\text { Mac-Moune } \\
\text { Lai et } \mathrm{al}^{14}\end{array}$} & $5 \mathrm{mo}$ & Female & Humerus & Yes & $\mathrm{n} / \mathrm{a}$ & Excision & AWD \\
\hline & $2 \mathrm{y}$ & Male & Radius, ulna forearm & Yes & Yes & Amputation, radiotherapy, & ANED \\
\hline $\begin{array}{l}\text { De Fatta } \\
\quad \text { et al } 15\end{array}$ & $3 \mathrm{y}$ & Male & $\begin{array}{l}\text { Hard palate, soft palate, } \\
\text { mucosa, submucosa }\end{array}$ & Yes & $\mathrm{n} / \mathrm{a}$ & Excision & ANED \\
\hline Zhu et $\mathrm{al}^{16}$ & $14 \mathrm{y}$ & Female & $\begin{array}{l}\text { T8-T9 vertebrae, rib heads } \\
\text { of T8-T9 }\end{array}$ & No & No & $\begin{array}{l}\text { Deformity correction (no } \\
\text { excision or other therapy) }\end{array}$ & $\begin{array}{l}\text { AWD (no significant } \\
\text { growth) }\end{array}$ \\
\hline \multirow[t]{2}{*}{$\begin{array}{l}\text { Alonso Arroyo } \\
\quad \text { et }^{1 l^{17}}\end{array}$} & $7 \mathrm{y}$ & Male & Scapula & Yes & Yes & $\begin{array}{l}\text { Prednisolone, vincristine, } \\
\text { cyclophosphamide, then } \\
\text { aspirin and interferon- } \alpha 2 b\end{array}$ & AWD \\
\hline & $4 \mathrm{mo}$ & Female & Scapula & Yes & Yes & $\begin{array}{l}\text { Prednisolone, vincristine, } \\
\text { interferon- } \alpha 2 b \text {, then } \\
\text { ticlopidine and aspirin }\end{array}$ & AWD \\
\hline
\end{tabular}

Abbreviations: ANED, alive with no evidence of disease; AWD, alive with disease; $\mathrm{n} / \mathrm{a}$, not available.

patient was then referred to our spinal oncological tertiary service in London.

Percutaneous needle biopsy was performed. Histologic sections consisted of a lobulated proliferation of thin-walled blood vessels with a prominent spindled pericytic component consistent with KHE. The lobulated vascular proliferation exhibited immunoreactivity for CD31, an immunomarker specific for vascular endothelium (Figure 4, left and right).

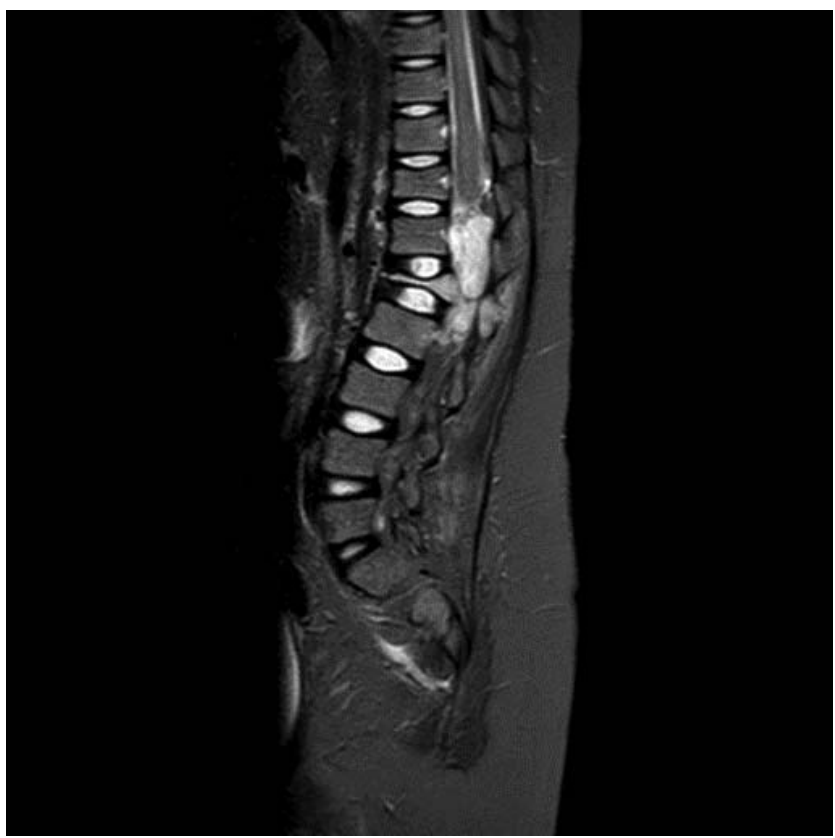

Figure 1. Sagittal MRI scan of the thoracolumar spine, September 2016.
A 2-stage anterior maximal debulking procedure and posterior instrumented stabilization was performed, as en bloc resection was not thought to be technically feasible (Figure 5, left and right). This led to a marked improvement in her neurological features and return to ambulation. Due to visa limitations, the patient returned to her native country, and adjuvant treatment was not given at that stage.

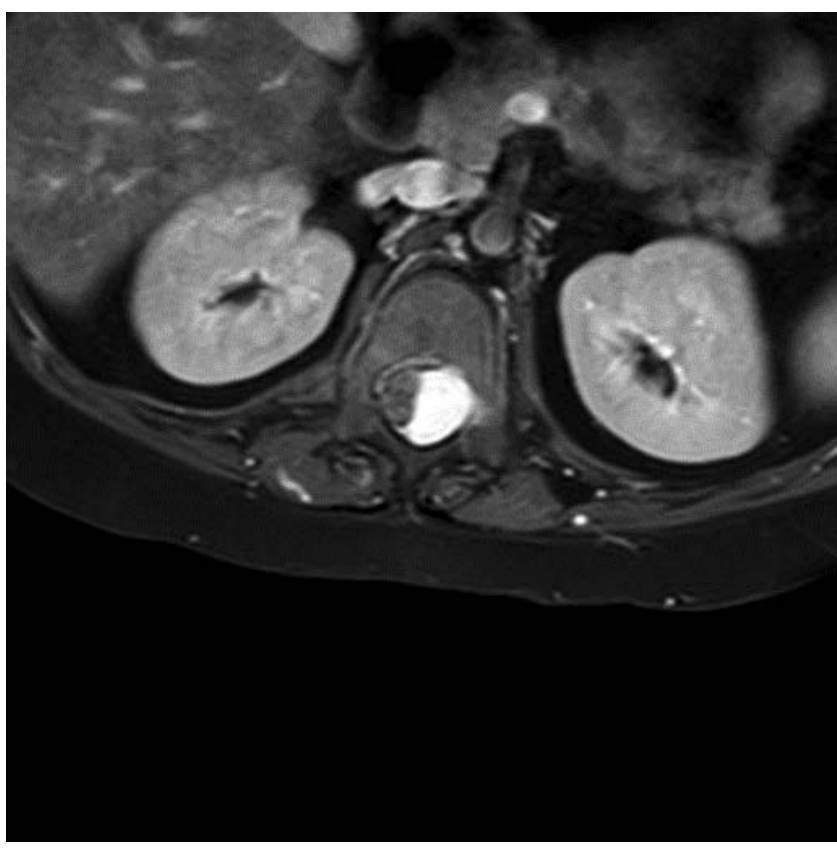

Figure 2. MRI scan, axial view through the level of the lesion T1, September 2016. 


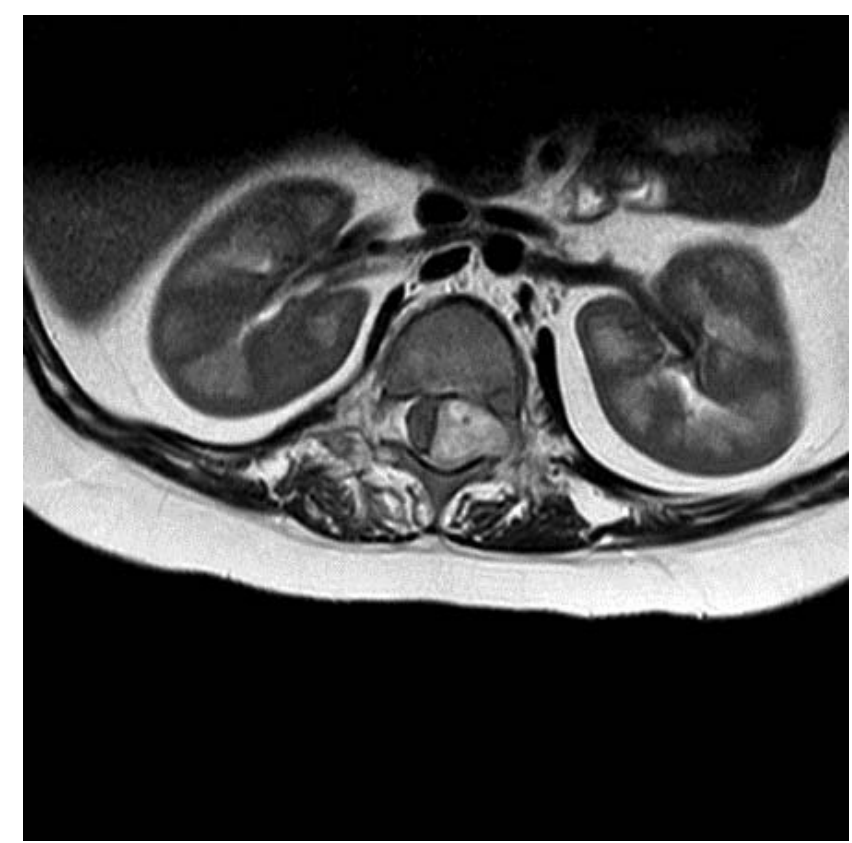

Figure 3. MRI scan, axial view through the level of the lesion T2, September 2016.

At 6-month review, the patient described worsening right knee pain. Bowel and bladder function remained intact, and ambulation was unaffected. Repeat MRI scan showed extensive local recurrence at L1/2, with the L2 and T12 vertebrae, previously spared, also now invaded by tumor (Figures 6 and 7).

A revision debulking resection was performed. This was complicated by significant hemorrhage from the tumor bed. Postoperative MRI (Figures 8 and 9) showed significant epidural hematoma with an ongoing risk of cord compression. Further surgery was not attempted due to the risk of catastrophic hemorrhage.
The patient received postoperative oral dexamethasone $(0.3 \mathrm{mg} / \mathrm{kg} / \mathrm{d})$. After 10 days, she recovered normal neurological function. Adjuvant treatment was then planned. Again, she was unable to remain in the United Kingdom and was treated in Turkey. Radiotherapy from T12 to L2 was undertaken. A course of oral sirolimus was attempted but was poorly tolerated, with a deterioration in back and leg pain, and so was discontinued. At 3-month review, the patient remained ambulant, with significant regression of the tumor on follow-up MRI. At 24-month clinical review, she remained neurologically normal. No further adjuvant treatment has been required. She has developed a mild kyphotic lumbar deformity secondary to her pathological fractures and surgical fixation.

Given the intralesional nature of the excision, she will require long-term radiological follow-up into adulthood, and intervention for her lumbar deformity may be required.

\section{DISCUSSION AND CONCLUSIONS}

KHE is a vascular neoplasm of intermediate malignancy, with a local infiltrative growth pattern and low-grade histomorphological features. ${ }^{11,18}$ Its biological behavior lies between infantile hemangioma and angiosarcoma. ${ }^{19}$

Pathological classification highlights a differentiation between infantile hemangioma, tufted angioma (TA), and KHE; however, some authors have described tumors exhibiting features that lie on a transitional spectrum between TA and KHE, even in specimens from the same patient ${ }^{20}$ (Table). KHE generally affects soft tissues, often with KMS, and has rarely been reported to affect bone. Twelve cases
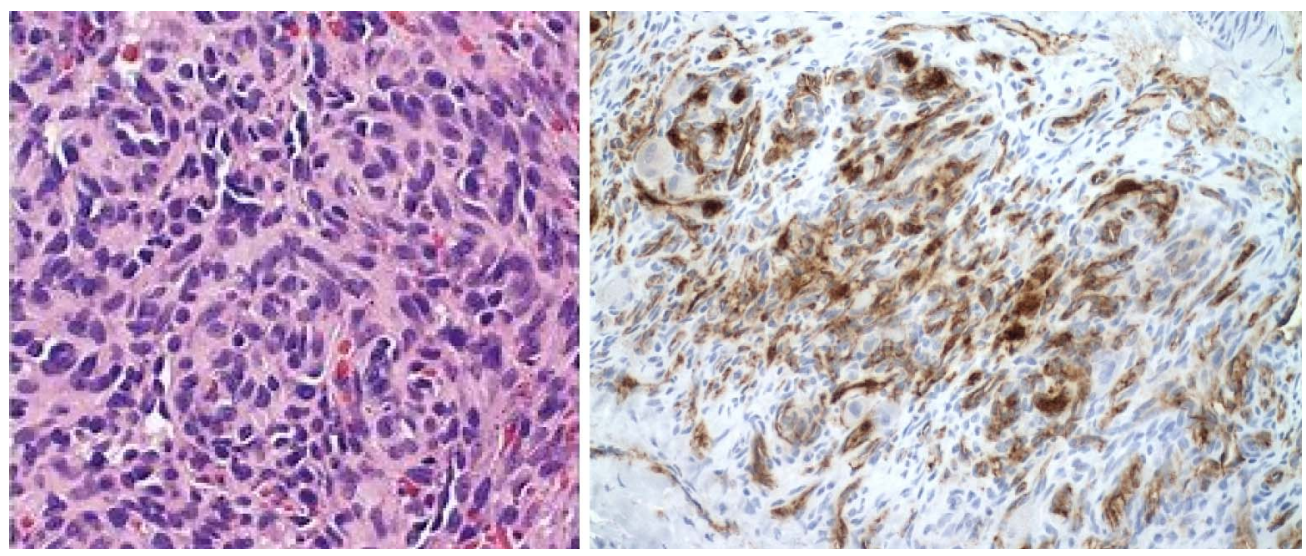

Figure 4. High-power view shows glomeruloid-like areas characterized by small, thin-walled vascular channels merging with rounded, epithelioid cells (stain: hematoxylin and eosin; original magnification $\times 600$; left). Immunohistochemistry for CD31 highlights small, slitlike vascular spaces of KHE (original magnification $\times 600$; right). 


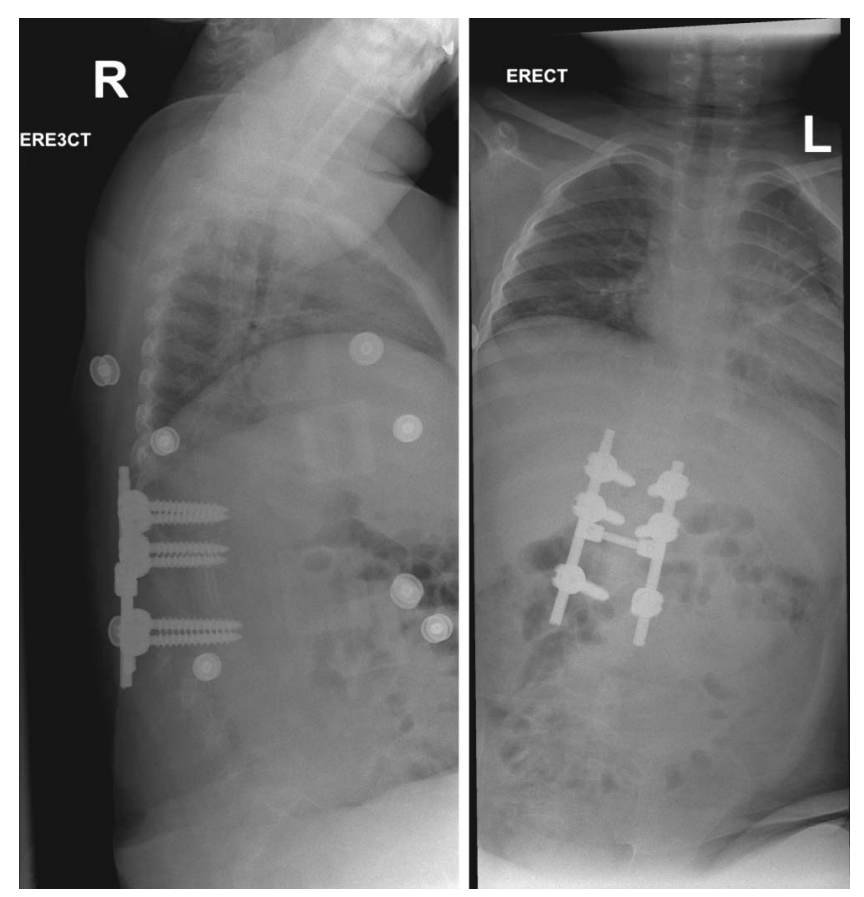

Figure 5. Lateral $x$-ray of the thoracolumbar spine, October 2016 (left). Anteroposterior x-ray of the whole spine, October 2016 (right).

of pediatric KHE involving bone have been previously described (Table).

Diagnosis of KHE is classically associated with KMS (characterized by profound thrombocytopenia, hemolytic anemia, and coagulopathy). While KMS is exclusively a recognized secondary of both TA and KHE, the literature suggests that KHE occurs in the absence of KMS in $29 \%-43 \%$ of

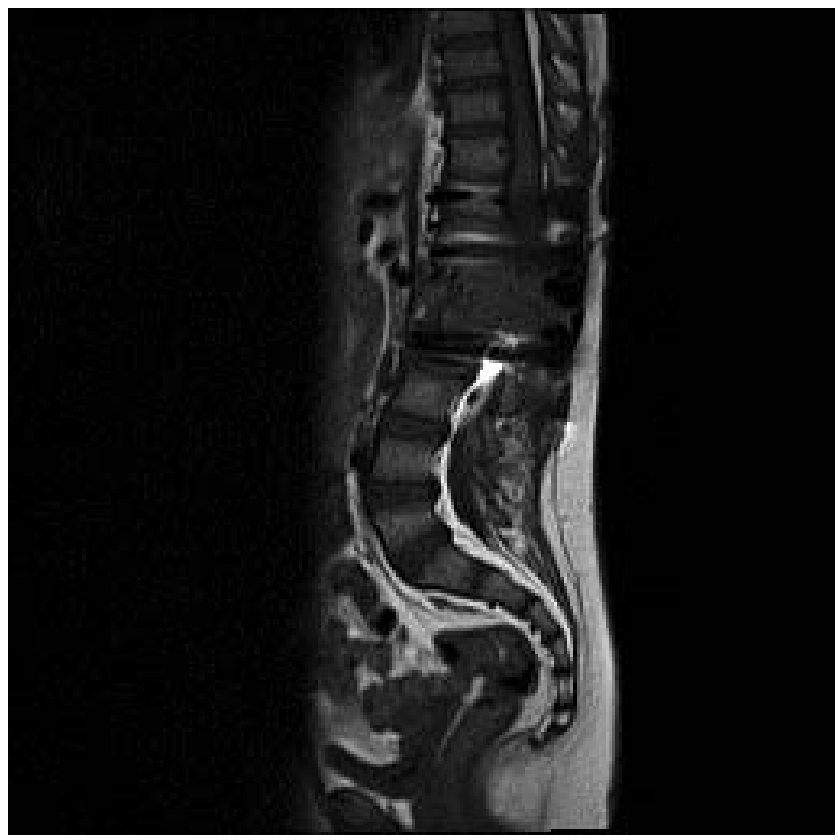

Figure 6. MRI scan of the thoracolumbar spine, February 2017.

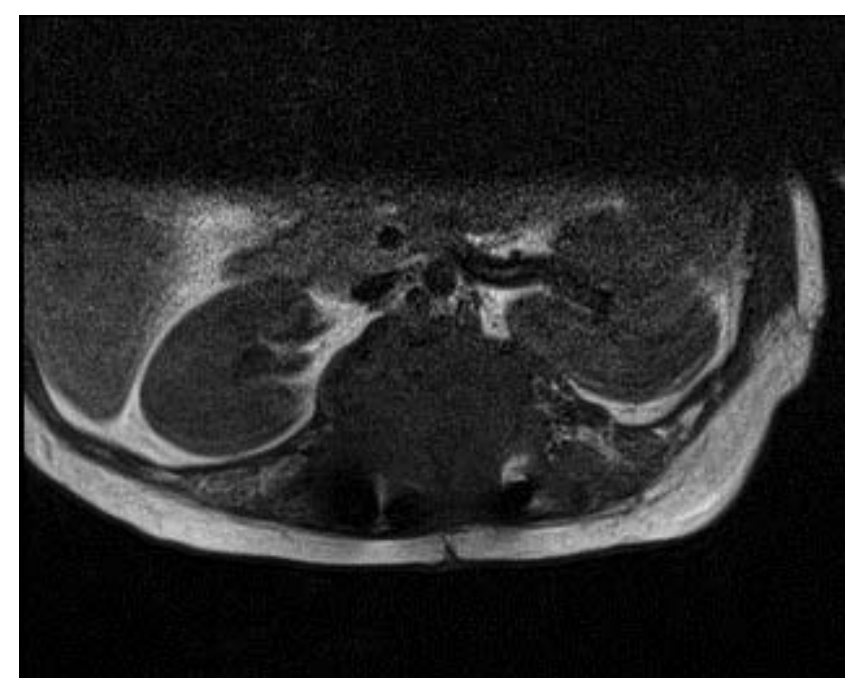

Figure 7. T2 MRI scan, axial view through the level of the lesion, February 2017

cases. $^{20,21}$ In the absence of cutaneous changes or KMS, KHE is a diagnostic challenge that may require biopsy, as clinical, laboratory, and radiographic features may be nonspecific. Radiographic bony invasion resembles rhabdomyosarcoma or aggressive fibromatosis, while differential diagnoses can be extensive and include tuberculosis, lymphoma, and round cell tumor.

Ryu et $\mathrm{al}^{22}$ present a series of 12 patients and summarize common radiographic findings. On unenhanced computed tomography, $86 \%$ exhibited homogenous iso-attenuation with adjacent muscle,

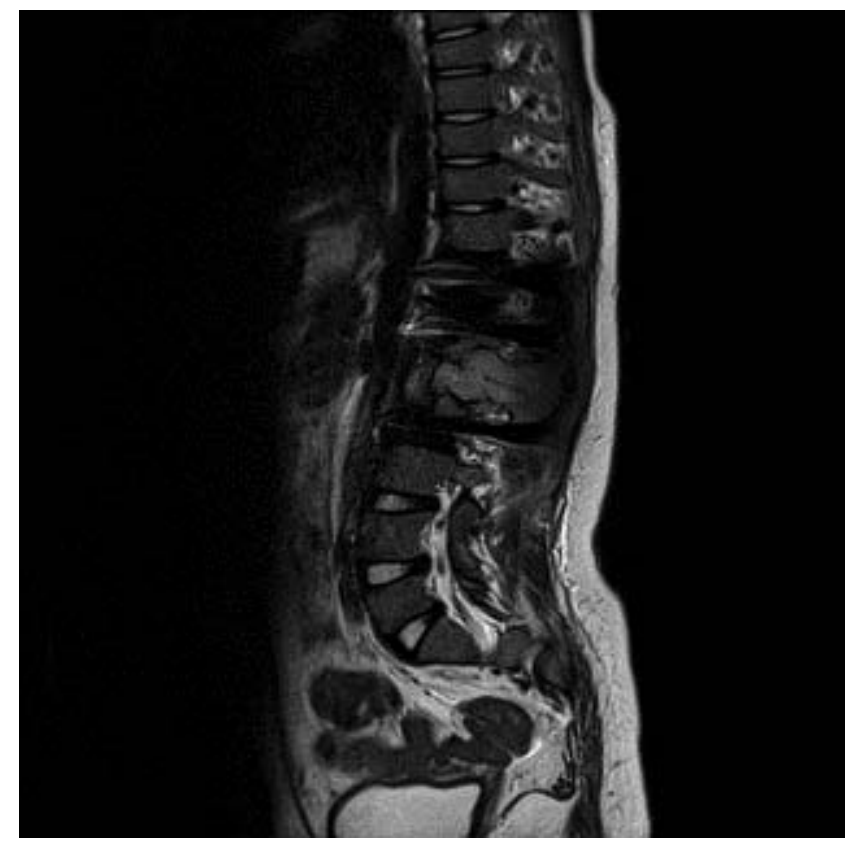

Figure 8. Sagittal T2 MRI scan of the thoracolumar spine, April 2017. 


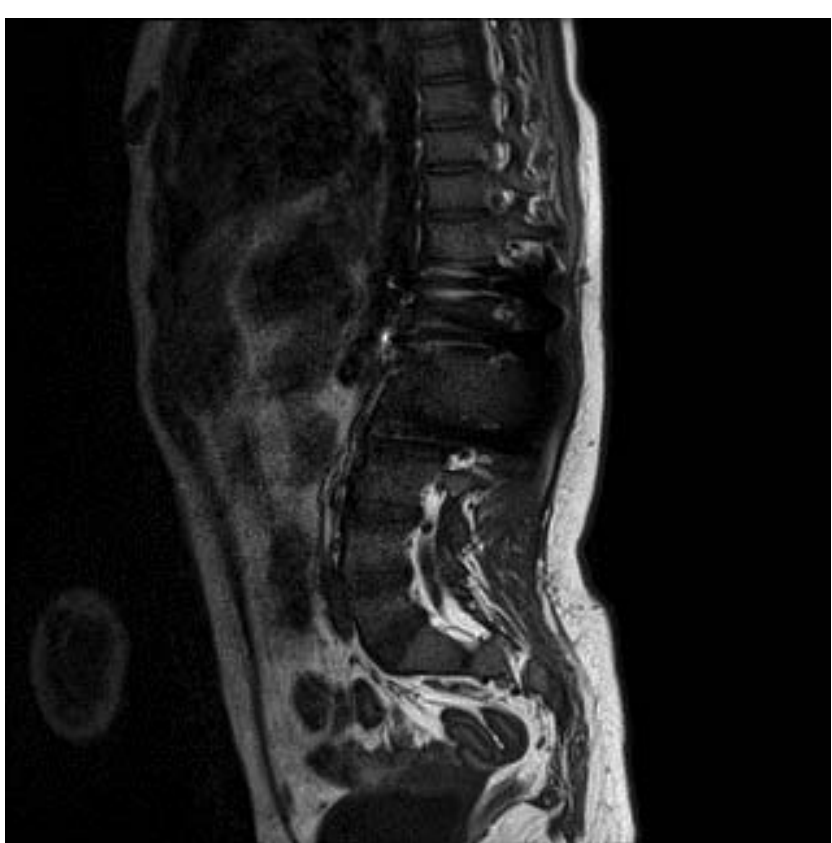

Figure 9. Sagittal MRI scan of the thoracolumar spine, April 2017

while only one case was homogeneously hypodense relative to muscle. After administration of contrast media, all exhibited heterogeneous enhancement. On MRI, all KHEs were heterogeneous and hyperintense relative to muscles on T2-weighted images. $^{22}$

Enjolras et $\mathrm{al}^{23}$ present a series of 22 cases. They report that KHEs exhibit "ill-defined margins and are characterised by multiplanar involvement, diffuse enhancement, iso-intensity relative to muscle on T1WI, hyperintensity on T2WI and destruction/ remodelling of adjacent bone." 24

The literature reveals a wide range of MRI findings regarding morphology, enhancement, and signal intensity, reflecting both the rarity of the condition and its variance in location of presentation.

Ryu et $\mathrm{al}^{22}$ categorize KHEs into 3 distinct classifications: (1) well-defined solid mass, (2) solid central mass with surrounding infiltrative regions, and (3) infiltrative lesion without definite solid regions. It is unclear whether this can be related to KHEs arising in the spine, and no association between classification and prognosis has yet been reported in the literature.

Biopsy is not commonly performed in KMS due to the risk of hemorrhage, so this must be excluded at an early stage. Histologically, KHE is characterized by "nodules or solid sheets of cytologically bland, monomorphic spindle cells forming sheets of slitlike capillary spaces and areas of tightly packed spindle cells . . . extravasation of red blood cells and haemosiderin deposits." 25

Fernandez et $\mathrm{al}^{14}$ report that KHE expresses lymphatic markers, such as D2-40 and vascular endothelial growth factor. It is also "typically" positive for CD34 and CD31 (Figure 4, right). There are a number of treatment modalities outlined in the literature. ${ }^{3,5,11,19,24,26}$

The lack of a consensus is due to the varying methods of presentation, difficulty in diagnosis, and disease rarity. Symptomatic KHE can progress rapidly, and complete en bloc surgical excision is thought to be a prime therapeutic option. ${ }^{26}$ However, no previous cases of en bloc surgical excision of spinal KHE have been reported.

Our case highlights the potential speed of local regrowth of this tumor, meaning that excision may be a technical challenge, especially when there is epidural extension. Weiss et $\mathrm{al}^{12}$ suggest that retroperitoneal lesions are typically extensive and unresectable, associated with KMS and with a high mortality.

In our case, a several-month course of neoadjuvant prednisolone was given in the United Arab Emirates prior to referral. This may have altered the vascularity of the lesion prior to her first surgery. During the first surgery, the tumor was relatively easy to manipulate, and hemostasis was not problematic. Embolization was avoided due to the location of the tumor with severe compression of the conus and concern regarding the potential for deterioration in neurological function as a result.

Prior to the second debulking surgery, this neoadjuvant steroid treatment did not occur. The tumor was more vascular, and the bleeding associated with intralesional resection was more challenging. Medical management is based largely on the treatment of other clinically aggressive vascular malformations. Radiation, ${ }^{27}$ embolization, ${ }^{28}$ interferon, and the chemotherapeutic regimen of actinomycin $\mathrm{D}$, thalidomide, and vincristine ${ }^{23}$ have proved useful in the treatment of isolated KHE. Management of KMS complicates treatment, with a multimodal approach using steroids, cytotoxic agents, and interferon possibly required. ${ }^{30}$

The decision to treat an isolated, noncoagulopathic KHE should be based on the size and location of the lesion and the compressive or infiltrative impact on surrounding structures. While Lyons et $\mathrm{al}^{1}$ insist that KHE would not regress in 
the absence of therapy, Zhu et $\mathrm{al}^{16}$ report a patient with KHE manifesting as pediatric scoliosis, rapidly progressing despite brace treatment. At 3-year follow-up, their case showed lesion progression despite the absence of resection or adjuvant therapy.

We present the first case of spinal KHE causing spinal cord compression managed surgically in the literature to date. Despite a lack of malignant potential, this case highlights the potentially locally aggressive nature of the lesion invading bone and the risk of neurological compromise. This feature makes en bloc resection with clear soft tissue margins technically difficult.

A number of treatment options have been reported with varying success on a variety of clinical presentations. This case highlights the potential pitfalls of debulking surgery alone when en bloc resection is not possible and adds to the sparse evidence base of this rare clinical entity.

We would suggest that neoadjuvant treatment with steroids and/or embolization be performed prior to surgery if possible and that intralesional debulking be avoided whenever possible and to strongly consider postoperative radiotherapy to the tumor bed postresection in an effort to avoid recurrence. We would be interested to know the success of medical management or radiotherapy for spinal cord compression secondary to infiltrative epidural KHE without surgery, although in this case we did not feel that a nonsurgical approach could be justified in a 7-year-old girl who had developed symptomatic spinal cord compression.

\section{REFERENCES}

1. Lyons LL, North PE, Mac-Moune Lai F, Stoler MH, Folpe AL, Weiss SW. Kaposiform hemangioendothelioma: a study of 33 cases emphasizing its pathologic, immunophenotypic, and biologic uniqueness from juvenile hemangioma. Am J Surg Pathol. 2004;28(5):559-568.

2. Zukerberg LR, Nickoloff BJ, Weiss SW. Kaposiform hemangioendothelioma of infancy and childhood: an aggressive neoplasm associated with Kasabach-Merritt syndrome and lymphangiomatosis. Am J Surg Pathol. 1993;17(4):321-328.

3. Werner JA, Dunne AA, Folz BJ, et al. Current concepts in the classification, diagnosis and treatment of hemangiomas and vascular malformations of the head and neck. Eur Arch Otorhinolaryngol. 2001;258(3):141.

4. Enjolras O, Mulliken JB. Vascular tumors and vascular malformations (new issues). Adv Dermatol. 1997;13:375-423.

5. Chung MT, Chen $\mathrm{CH}$, Chiu $\mathrm{CH}$, Yang $\mathrm{CP}$, Hsueh $\mathrm{C}$, Jaing TH. Successful nonoperative therapy for kaposiform hemangioendothelioma involving the neck: report of 1 case. Otolaryngol Head Neck Surg. 2003;129:605-607.

6. Hardisson D, Prim MP, De Diego JI, Patrón M,
Escribano A, Rabanal I. Hemangioendothelioma of the external auditory canal in an adult. Head Neck. 2002;24:614617.

7. Fukunaga M, Ushigome S, Ishikawa E. Kaposiform hemangioendothelioma associated with Kasabach-Merritt syndrome. Histopathology. 1996;28(3):281-284.

8. Blei F, Karp N, Rofsky N, et al. Successful multimodal therapy for kaposiform hemangioendothelioma complicated by Kasabach-Merritt phenomenon: case report and review of the literature. Pediatr Hematol Oncol. 1998;15(4):295-305.

9. Brasanac D, Janic D, Boricic I, et al. Retroperitoneal kaposiform hemangioendothelioma with tufted angioma-like features in an infant with Kasabach-Merritt syndrome. Pathol Int. 2003;53(9):627-631.

10. Lisle $\mathrm{J}$, Bradeen $\mathrm{H}$, Kalof $\mathrm{A}$, et al. Case report: kaposiform hemangioendothelioma in multiple spinal levels without skin changes. Clin Orthop Relat Res. 2009;467(9):24642471 .

11. Ma J, Shi Q, Jiang S, Zhou H, Zhou X. Primary kaposiform hemangioendothelioma of a long bone: two cases in unusual locations with long-term follow up. Pathol Int. 2011;61:382-386.

12. Lalaji TA, Haller JO, Burgess RJ. A case of head and neck kaposiform hemangioendothelioma simulating a malignancy on imaging. Pediatr Radiol. 2001;31:876-878.

13. Gruman A, Liang M, Mulliken J, et al. Kaposiform hemangioendothelioma without Kasabach-Merritt phenomenon. J Am Acad Dermatol. 2005 Apr;52(4):616-622.

14. Mac-Moune Lai F, To K, Choi P. Kaposiform hemangioendothelioma: five patients with cutaneous lesion and long follow-up. Mod Pathol. 2001;14,1087-1092.

15. DeFatta RJ, Verret DJ, Adelson RT, Gomez A, Myers LL. Kaposiform hemangioendothelioma: case report and literature review. Laryngoscope. 2005;115:1789-1792.

16. Zhu Y, Qiu G, Zhao H, Liang J, Shi X. Kaposiform hemangioendothelioma with adolescent thoracic scoliosis: a case report and review of literature. Eur Spine J. 2011;20 Suppl 2(Suppl 2):S309-S313.

17. Alonso Arroyo V, Lopez-Gutierrez JC, Martinez R, Fernandez-Pineda I. Identical presentation of scapular osteolysis in two patients with thoracic kaposiform hemangioendothelioma. Pediatr Dermatol. 2017;34:e146-e149.

18. Weiss SW, Goldblum JR. Hemangioendothelioma: vascular tumors of intermediate malignancy. In: Enzinger FM, Weiss SW, eds. Soft Tissue Tumors. 5th ed. St Louis, MO: Mosby Elsevier; 2008:688-693.

19. Niedt GW, Greco MA, Wieczorek R, Blanc WA, Knowles DM. Hemangioma with Kaposi's sarcoma-like features: report of two cases. Pediatr Pathol. 1989;9(5):567-575.

20. Fernandez Y, Bernabeu-Wittel, Garcia-Morillo JS. Kaposiform hemangioendothelioma. Eur J Intern Med. 2009;20(2):106-113.

21. Fukunaga M, Ushigome S, Ishikawa E. Kaposiform hemangioendothelioma associated with Kasabach-Merritt syndrome. Histopathology. 1996;28(3):281-284.

22. Ryu YJ, Choi YH, Cheon JE, et al. Imaging findings of kaposiform hemangioendothelioma in children. Eur J Radiol. 2017;86:198-205.

23. Enjolras O, Mulliken JB, Wassef M, et al. Residual lesions after Kasabach-Merritt phenomenon in 41 patients $J$ Am Acad Dermatol. 2000;42(2):225-235. 
24. Enjolras O, Wassef M, Mazoyer E, et al. Infants with Kasabach-Merritt syndrome do not have true hemangiomas. $J$ Pediatr. 1997;130(4):631-640.

25. Sarkar M, Mulliken JB, Kozakewich HP, Robertson RL, Burrows PE. Thrombocytopenic coagulopathy (KasabachMerritt phenomenon) is associated with kaposiform hemangioendothelioma and not with common infantile hemangioma. Plast Reconstr Surg. 1997;100(6):1377-1386.

26. Beaubien ER, Ball NJ, Storwick GR. Kaposiform hemangioendothelioma: a locally aggressive vascular tumor. $J$ Am Acad Dermatol. 1998;38(5 Pt 2):799-802.

27. Hardisson D, Prim MP, Diego JI, et al. Kaposiform hemangioendothelioma of the external auditory canal in an adult. Head Neck. 2002;24(6):614-617.

28. Sarkar M, Mulliken JB, Kozakewich HP, Robertson RL, Burrows PE. Thrombocytopenic coagulopathy (KasabachMerritt phenomenon) is associated with kaposiform hemangioendothelioma and not with common infantile hemangioma. Plast Reconstr Surg. 1997;100(6):1377-1386.

29. Hauer J, Graubner U, Konstantopoulos N, et al. Effective treatment of kaposiform hemangioendotheliomas associated with Kasabach-Merritt phenomenon using fourdrug regimen. Pediatr Blood Cancer. 2007;49(6):852-854.

30. Hu B, Lachman R, Phillips J, et al. Kasabach-Merritt syndrome-associated kaposiform hemangioendothelioma successfully treated with cyclophosphamide, vincristine, and actinomycin D. J Pediatr Hematol Oncol. 1998;20(6):567-569.

Disclosures and COI: Ethics approval was waived by the Royal National Orthopaedic Hospital ethics board, as this case report did not involve a study or use of experimental treatment but was rather a retrospective report of treatment as per protocol that had already been completed. Consent for publication was sought from the legal guardian (mother) of the child, whose plain radiographs and MRI scans are included in this report. The authors declare that they have no competing interests. No funding was sought for this study. KE wrote the manuscript. HA reviewed and edited the manuscript.

Corresponding Author: Kelechi Eseonu, FRCS, MSc (Oxon), Spinal Deformity Unit, Royal National Orthopaedic Hospital, Stanmore HA7 4LP, United Kingdom; Email: kelechi.eseonu@ doctors.org.uk.

Published 30 June 2020

This manuscript is generously published free of charge by ISASS, the International Society for the Advancement of Spine Surgery. Copyright (c) 2020 ISASS. To see more or order reprints or permissions, see http://ijssurgery.com. 